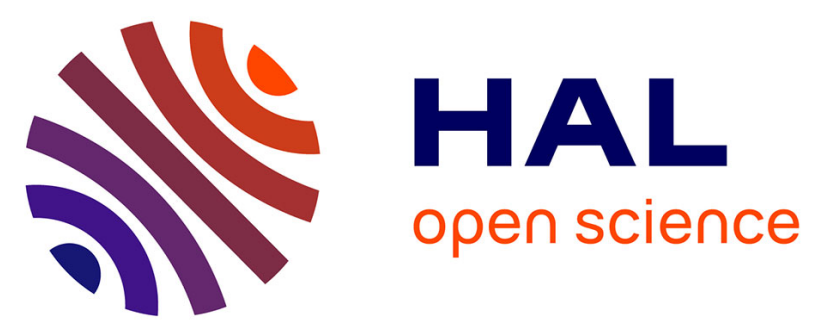

\title{
First analysis of the misaligned leading edges of ITER-like Plasma Facing Units using a very high resolution infrared camera in WEST
}

A Grosjean, Y Corre, R Dejarnac, J Gaspar, J P Gunn, S

Carpentier-Chouchana, E Delmas, X. Courtois, G de Temmerman, M Diez, et al.

\section{To cite this version:}

A Grosjean, Y Corre, R Dejarnac, J Gaspar, J P Gunn, et al.. First analysis of the misaligned leading edges of ITER-like Plasma Facing Units using a very high resolution infrared camera in WEST. Nuclear Fusion, 2020. hal-03148253

\section{HAL Id: hal-03148253 \\ https://hal-amu.archives-ouvertes.fr/hal-03148253}

Submitted on 22 Feb 2021

HAL is a multi-disciplinary open access archive for the deposit and dissemination of scientific research documents, whether they are published or not. The documents may come from teaching and research institutions in France or abroad, or from public or private research centers.
L'archive ouverte pluridisciplinaire HAL, est destinée au dépôt et à la diffusion de documents scientifiques de niveau recherche, publiés ou non, émanant des établissements d'enseignement et de recherche français ou étrangers, des laboratoires publics ou privés. 


\title{
First analysis of the misaligned leading edges of ITER-like Plasma Facing Units using a very high resolution infrared camera in WEST
}

\author{
A. Grosjean ${ }^{1}$, Y. Corre, R. Dejarnac ${ }^{\text {a }}$, J. Gasparb , J. P. Gunn, S. Carpentier-Chouchana ${ }^{\text {, }}$ \\ X. Courtois, E. Delmas, G. De Temmerman', M. Diez, L. Dubus, A. Durocher ${ }^{c}$, F. \\ Escourbiac $^{c}$, M. Firdaouss, J. Gerardin' ${ }^{a}$, M. Houry, R.A. Pitts ${ }^{c}$, C. Pocheau, E. Tsitrone, \\ and the WEST team*
}

\author{
CEA, IRFM, F-13108 Saint-Paul-Lez-Durance, France \\ anstitute of Plasma Physics, Czech Academy of Sciences, 18200 Prague, Czech Republic \\ ${ }^{b}$ Aix Marseille Univ, CNRS, IUSTI, Marseille, France \\ 'ITER Org, Route Vinon Sur Verdon, CS 90 046, F-13067 St Paul Les Durance, France \\ * See http://west.cea.fr/WESTteam
}

${ }^{1}$ Corresponding author e-mail: alex.grosjean@cea.fr

Twelve ITER-like plasma-facing units made of tungsten were exposed in the WEST tokamak divertor, with three PFUs significantly overexposed to plasma heat flux: one sharp-edged PFU (vertical misalignment $h=0.8 \mathrm{~mm}$ ) and two chamfered PFUs $(h=0.6 \mathrm{~mm}$ and $0.3 \mathrm{~mm}$, respectively). This paper describes the first temperature analysis obtained with a very high spatial resolution infrared camera (pixel size $\sim 0.1 \mathrm{~mm}$ ) on the misaligned PFU edges and shows the consistency obtained on the parallel heat flux derived from these measurements. The analysis is focused on the hottest areas of the PFU misaligned leading edges, since the temperature detection threshold of the VHR camera is high $\left(T_{\text {threshold, } \mathrm{BB}} \approx 370^{\circ} \mathrm{C}\right)$. The heat flux parallel to the magnetic field lines is assessed by matching the toroidal temperature profile in the vicinity of the leading edge with 3D finite element modelling. The tungsten emissivity assumed in this study is 0.6 , consistent with laboratory measurements for damaged PFUs. For the three PFUs studied (with different vertical misalignments, incident angles, geometries), the derived parallel heat flux is similar, and consistent with independent measurements by a Fiber Bragg grating embedded in a graphite PFU at another toroidal location, giving confidence in future experiments using the same settings.

\section{Introduction}

Fusion reactors face high and steady-state heat fluxes on the divertor targets. In ITER, activelycooled plasma-facing units (PFUs) consisting of tungsten (W) monoblocks (MB) bonded to poloidally-running CuCrZr cooling tubes are foreseen for bearing the high power coming from the plasma (see left panel of Figure 1). In order to provide a sufficient margin to avoid critical 
heat flux on top surface $\left(q_{\text {top }}\right)$ [1] while simultaneously preventing the formation of macrocracks due to deep tungsten recrystallization, the heat load from plasma, radiation, and energetic neutrals must not exceed $16 \pm 2 \mathrm{MW} / \mathrm{m}^{2}$ [2]. The divertor is designed such that the plasma flowing along magnetic field lines impacts the MB top surfaces at glancing angles of $\sim 4.5^{\circ}$. This angle includes a $0.5^{\circ}$ tilting angle of the divertor cassettes, designed to protect their leading edges, and $1^{\circ}$ toroidal beveling of the individual MBs to avoid exposing their poloidal leading edges [3]. In the worst case of negligible contributions from radiation and neutrals, the maximum allowed plasma heat flux parallel to the magnetic field lines would be $q_{/ /} \approx 200 \mathrm{MW} \cdot \mathrm{m}^{-2}$. Without toroidal beveling, magnetic field lines can penetrate the poloidal gaps (PG) between PFUs and strike the exposed leading edges (LE) with near-normal incidence, leading to higher localized heat fluxes. This effect is enhanced by possible misalignments between MBs, which can lead to melting on the over-exposed leading edges (see right panel of Figure 1).
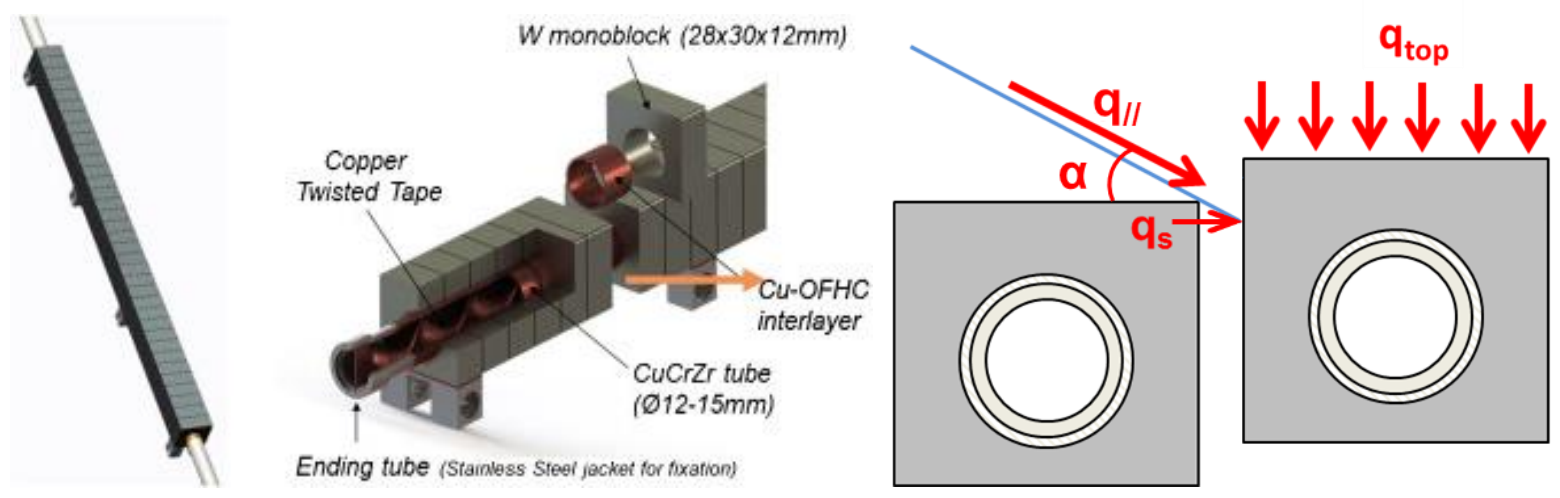

Figure 1. Left panel: ITER-like PFU technology used in WEST. The PFU is composed of 35 bulk tungsten monoblocks bonded to poloidally-running CuCrZr cooling tubes with a copper twisted taped in the actively cooled system. This technology requires toroidal gaps (between MB) and poloidal gaps (between PFU) to withstand thermomechanical stress. Right panel: magnetic field line impacting the side of the misaligned monoblock (blue line) with a parallel heat flux coming from the scrape off layer (q//) and an incidence angle ( $\alpha$ ). Heat flux absorbed on the top surface $\left(q_{t o p}\right)$, and on the side surface $\left(q_{s}\right)$ are also depicted on the misaligned MB.

The main solution to protect the leading edges in ITER is to shape the MB surface [4]. Several numerical studies have been performed for ITER, assuming the optical, or guiding center approximation, meaning that the particles' Larmor orbits do not lead to significant smoothing of the heat flux profile incident on surfaces in the vicinity of magnetic shadows (a valid approximation for inter-ELM plasmas [3]), with an extensive set of shaping [5],[6]. Assembly tolerance on the radial misalignment between toroidally neighboring PFCs is limited to $\pm 0.3 \mathrm{~mm}$, for this reason ITER Organization (IO) decided to introduce a $0.5 \mathrm{~mm}$ toroidal bevel which is a trade-off allowing to magnetically shadow the leading edge but reducing the plasma wetted area and thereby increasing the heat flux absorbed on the top surface [4],[7]. As the ITER decision was taken after launching the WEST project, the first series of PFUs tested in WEST do not incorporate beveling to protect the leading edges; some PFUs have $1 \mathrm{~mm}$ 
chamfers and the others have sharp leading edges. The study presented in this paper nonetheless provides validation of IR analysis and confirmation of leading edge heating of unshaped MBs. Regarding the major impact on plasma performance and tokamak maintenance in WEST and ITER, it is important to numerically and experimentally study the thermal behavior of MBs in a relevant tokamak environment under magnetized plasma heat flux.

This paper reports on the first thermal analysis performed on ITER-like PFUs exposed in the WEST tokamak, using a very high spatial resolution infra-red camera (IR) to monitor misaligned leading edges. It is organized as follows, a background on LE in tokamaks and a focus on WEST features are proposed in Section 2. The experimental configuration is presented in Section 3, including the metrological analysis performed on the mixed divertor sector, the VHR IR system with emissivity correction, and the WEST experiment performed to study the shaping and leading edge of the ITER-like PFUs. Section 4 describes the IR data processing, the heat flux and thermal modelling leading to synthetic IR data production. Section 5 shows the results obtained for two different geometries (sharp, chamfered), three different PFU misalignments, and three different toroidal locations (scanning the incident angle from minimum to maximum due to the ripple effect). The summary and discussion are proposed in Section 6.

\section{Background}

Experimental studies on leading edges through IR thermography have already been performed on several devices, with different magnetic equilibria such as limiter or divertor configuration or on linear devices, with different components and geometries, but never on a real, actively cooled ITER-like W PFU. The first study on actively cooled PFUs was performed with the toroidal pump limiter (TPL) of Tore Supra. The TPL was made of carbon fiber composite (CFC) tiles with a flat top surface and $2 \mathrm{~mm}$ rounded edges, including poloidal and toroidal gaps [8]. The pixel size of the IR thermography system was $3.1 \mathrm{~mm}$ and misalignment between two neighboring fingers located in the field of view of the IR system was $h=0.2 \mathrm{~mm}$. A series of experiments [9] has also been conducted in the COMPASS tokamak with a specially designed graphite inner wall limiter (IWL). Calibrated misalignments in the range of $0.1-$ $1 \mathrm{~mm}$ were deliberately introduced with a $0.3 \mathrm{~mm} /$ pixel IR system to monitor the temperature of the LE. In JET, running with an ITER-like wall, a sharp edge [10] and a protruding [11] W lamella (15 ${ }^{\circ}$ slope), have been exposed to L-mode [12] and H-mode [13], [14] plasmas monitored with a $1.7 \mathrm{~mm} /$ pixel IR system. On ASDEX-Upgrade, an extensive series of experiments in $\mathrm{H}$-mode have been performed on misaligned and $15^{\circ}$ sloped tiles using its Divertor Manipulator II system (DIM-II) up to $1.1 \mathrm{~mm}$ to observe tungsten melt motion [15]. Textor also ran experiments on tungsten melt motion with castellated $\mathrm{W}$ plates 


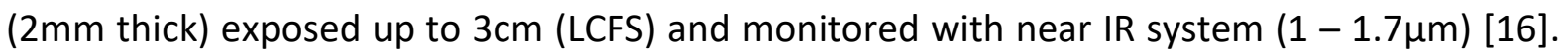
Tungsten blocks with 0.3 and $1 \mathrm{~mm}$ misalignments have been exposed in DIII-D Helium plasmas viewed with a high-resolution IRTV system [17]. The KSTAR device has exposed some W blocks with misalignment from $0.3 \mathrm{~mm}$ up to $2 \mathrm{~mm}$ monitored with $0.4 \mathrm{~mm} /$ pixel IR system [18]. Magnum PSI and PILOT-PSI respectively run an extensive set of linear plasma with grazing angles $\left(4-7^{\circ}\right)$ in misaligned $W$ block to replicate L-mode and $\mathrm{H}$-mode tokamak divertor-like, with $0.4 \mathrm{~mm} /$ pixel IR system [19], [20]. The work reported in this paper shows first thermal analysis of misaligned actively cooled ITER-like PFUs exposed in the WEST tokamak, monitored with a $0.1 \mathrm{~mm} /$ pixel IR system.

WEST (W Environment in Steady-state Tokamak) is an actively cooled, medium sized tokamak with 18 superconducting toroidal magnetic field coils. As a result of the natural toroidal field ripple, the incidence angle of the magnetic field lines striking the divertor has a sinusoidal modulation with a $20^{\circ}$ periodicity in the toroidal direction (see Figure 2 ).

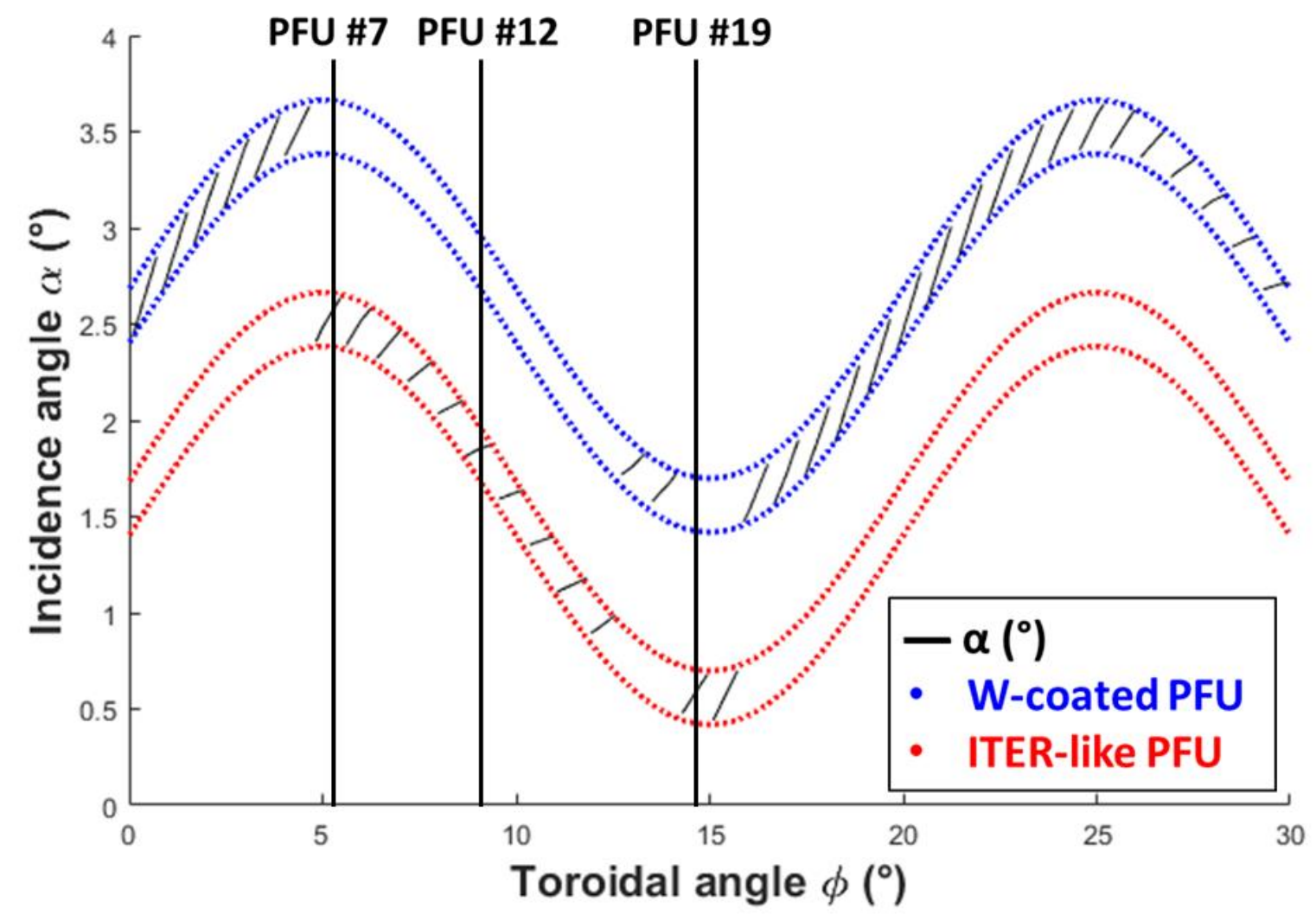

Figure 2. Spatial variation of the incidence angle $(\alpha)$ as function of the toroidal angle $(\phi)$ in the test divertor sector for the outer strike point (OSP) on MB27. Blue and red areas show respectively the incidence angle for inertial beveled W-coated graphite PFUs and unbeveled W ITER-like PFUs having a lower incidence angle. The three averaged incidence angles are respectively $2.5^{\circ}, 1.9^{\circ}$ and $0.6^{\circ}$ for the misaligned PFU \#7, PFU \#12 and PFU \#19 (see Section 2.1). 
The WEST lower divertor has 12 sectors each equipped with 38 PFUs. During the C3 experimental campaign achieved in 2018, most of these PFUs were made of uncooled Wcoated graphite components. One sector, called the "test divertor sector", was equipped with a set of 12 ITER-like PFU prototypes [21], each composed of 35 tungsten monoblocks (MBs) and separated toroidally by $0.5 \mathrm{~mm}$ gaps (see Figure 3). Among them, 2 have sharp LEs and 10 have a $1 \times 1 \mathrm{~mm} 45^{\circ}$ chamfer on the LEs. The PFUs were tested in WEST under plasma discharges heated by a lower hybrid (LH) heating system with injected power up to $\sim 5 \mathrm{MW}$. The ITER-like PFUs are observed by a very high-resolution (VHR) infra-red camera in the short wavelength IR band (SWIR: $\lambda=1.6$ to $2.1 \mu \mathrm{m}$ ) [22].
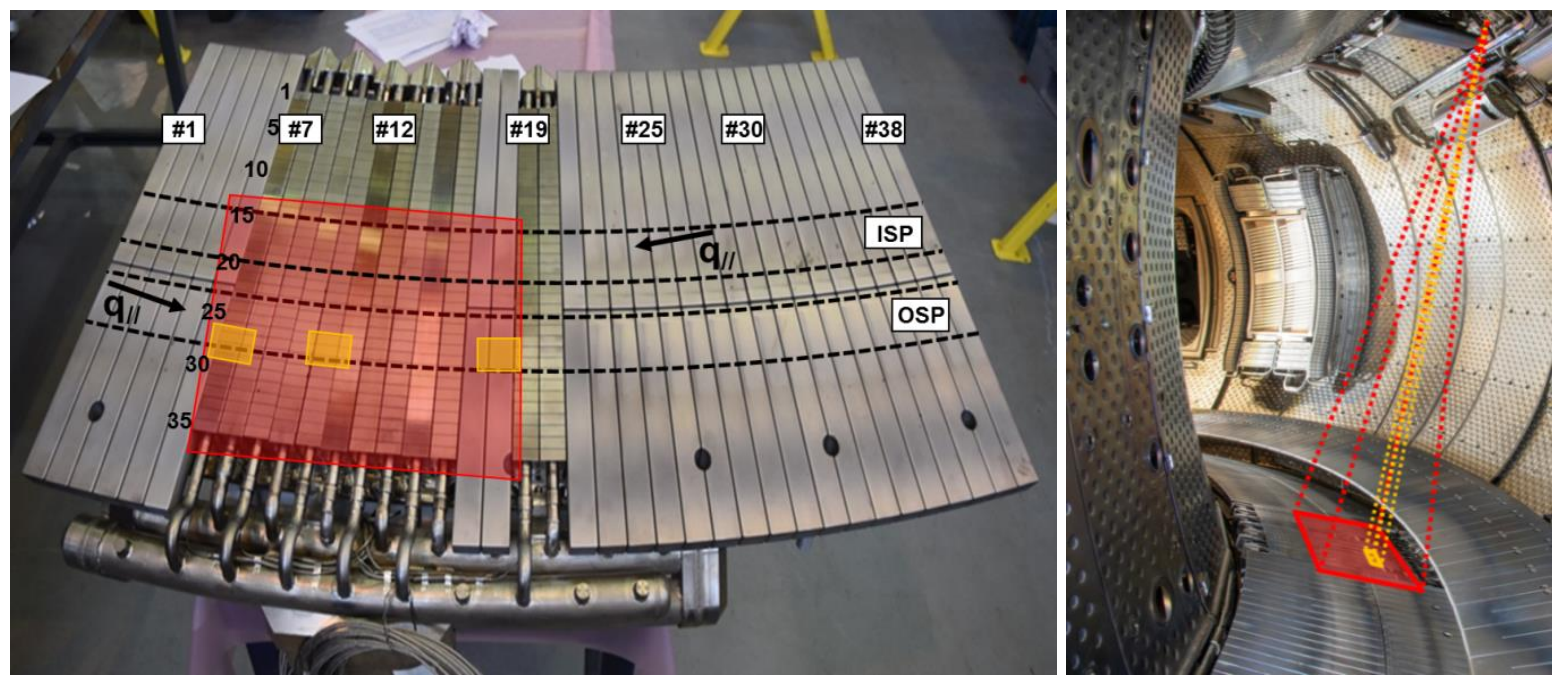

Figure 3. Left: the WEST test divertor sector including inertial beveled W-coated graphite PFUs (26) and unbeveled ITER-like PFUs with sharp (2) and chamfered (10) leading edges before the C3 experimental campaign performed in 2018. PFUs monitored by the VHR IR camera are shown in the red areas from PFU \#6 to PFU \#19. Orange areas are shown to visualize the three regions of interest (ROIs) monitored by the VHR IR camera on PFU \#7 \#12 \& \#19, discussed in this paper. Black arrows indicate the parallel heat flux direction in inner (HFS) and outer (LFS) divertor. MBs are labeled from MB1 (HFS) to MB35 (LFS). Right: tangential view of the WEST vacuum vessel showing the VHR IR FoV (orange) and the potential position that can be observed with the VHR (red).

Prior to the plasma experiments, a metrological study was performed with a 3D measuring arm to evaluate the vertical misalignments between neighboring ITER-like PFUs. The study revealed that 3 out of 12 of the ITER-like PFU are of interest with a vertical misalignment higher than the ITER tolerance of $\pm 0.3 \mathrm{~mm}$. This is due to the assembly procedure, which was not yet optimized for installing new ITER like PFU between previously implemented ITER like PFU, as was required for the C3 campaign (2018). Based on this feedback, the assembly procedure has been successfully adjusted for the C4 campaign (2019). The aim of this paper is to investigate the heating and thermal response of these overexposed leading edges in the C3 campaign (up to $0.8 \mathrm{~mm}$ ) as function of the plasma heat flux which is determined by matching the toroidal temperature profile in the vicinity of the leading edge with 3D finite element modelling. Embedded thermocouple (TC) and Fiber Bragg Grating (FBG) temperature 
measurements performed on the W-coated graphite PFUs [23] are used to crosscheck the parallel heat flux derived from the IR camera.

\section{Experimental configuration}

\subsection{Metrological study on WEST test divertor sector}

A detailed metrological study was performed after the PFUs were assembled and before they were installed in the WEST plasma vessel for the 2018 campaign, using a 3D ball probe measuring arm which has a $\pm 18 \mu \mathrm{m}$ precision. Planes defining the top surface for each PFU are replicated with the least square method to match the probe measurement. For the ITERlike PFUs, which are not beveled, a single plane is used. The inertial W-coated graphite PFUs have a $0.5 \mathrm{~mm}$ toroidal bevel in the high heat flux areas to protect their LEs. They have been split into three planes: one for the inner tile with the $0.5 \mathrm{~mm}$ bevel on the HFS, one for the outer tile with the $0.5 \mathrm{~mm}$ bevel inclined in the opposite direction on the LFS, and one for the un-shaped part in the private flux region (PFR) of both inner and outer tiles [24].

The misalignments are then computed PFU by PFU with respect to the theoretical positions given by a 3D CAD model of the sector at the standard outer strike point position. The standard inner strike point (ISP) and outer strike point (OSP) areas are $4 \mathrm{MB}$ wide respectively from MB14 to MB18 and from MB23 to MB27, depending on the magnetic configuration used during the discharge (see Figure 3). Only the OSP region will be discussed in this paper, as this is the most loaded area with best VHR IR camera data. Experiments discussed in this paper have been performed with the OSP located on MB27. The overall view of the PFU top surface is shown in the left panel of Figure 4 along a toroidal cut at the outer strike point (OSP). Numerical values are given in the table 1 :

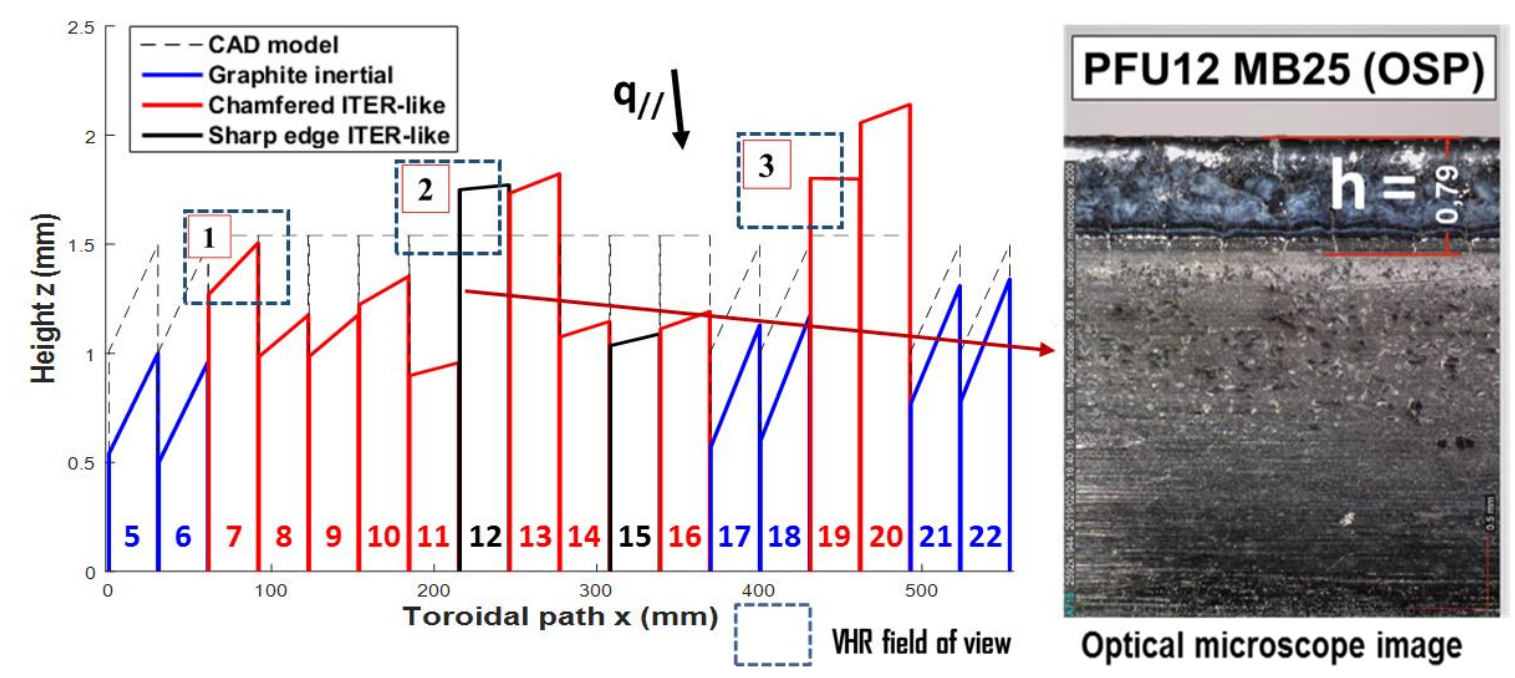

Paper: First analysis of the misaligned leading edges of ITER-like Plasma Facing Units using a very high resolution infrared camera in WEST - A. GROSJEAN - 21/04/2020 
Figure 4. Left: top surface of the test divertor sector along a toroidal cut from PFU \#5 to PFU \#22. The parallel heat flux direction is given for an incidence angle of $2^{\circ}$. Note the scale here is deliberately greatly exaggerated to be able to visualize the sub-millimeter misalignment measured during the metrological study. ITER-like PFUs without bevel on the top surface are shown, having either a $1 \times 1 \mathrm{~mm} 45^{\circ}$ chamfer (red) or sharp edges (black). Blue PFUs correspond to W-coated graphite PFU with rounded edges ( $r=2 \mathrm{~mm}$ ) and $0.5 \mathrm{~mm}$ bevel $\left(1^{\circ}\right)$ on the top surface. Black dashed lines correspond to the CAD model. The three fields of view used in this paper are represented with a blue rectangle. Right: optical microscope image on the sharp leading edge PFU \#12, MB25 after the 2018 experimental campaign.

\begin{tabular}{|c|c|c|c|c|c|c|c|c|c|c|c|c|c|c|}
\hline PFU\# & PFU7 & PFU8 & PFU9 & PFU10 & PFU11 & PFU12 & PFU13 & PFU14 & PFU15 & PFU16 & PFU17 & PFU18 & PFU19 & PFU20 \\
\hline $\mathrm{h}(\mathrm{mm})$ & 0,31 & $-0,52$ & $-0,19$ & 0,05 & $-0,45$ & 0,79 & $-0,04$ & $-0,75$ & $-0,11$ & 0,02 & $-0,62$ & $-0,53$ & 0,63 & 0,25 \\
\hline
\end{tabular}

Table 1. Vertical misalignment from a PFU to its previous neighbor $(\mathrm{mm})$ measured at the OSP. Positive values correspond to exposed leading edges while negative values correspond to shadowed leading edges.

In the OSP region, the metrological study reveals three vertical misalignments that exceed the ITER assembly tolerances ( $\mathrm{h}> \pm 0.3 \mathrm{~mm}$ ), on PFU \#7 ( $\mathrm{h}=0.31 \mathrm{~mm}$ - chamfered), on PFU \#12 ( $\mathrm{h}=0.79 \mathrm{~mm}$ - sharp) and on PFU \#19 ( $\mathrm{h}=0.63 \mathrm{~mm}$ - chamfered). Exposed leading edges are located at three different toroidal positions with three different incidence angles $\left(2.5^{\circ}, 1.9^{\circ}\right.$ and $0.6^{\circ}$ ) due to the ripple effect as described in Figure 2.

A visual and microscopic inspection was carried out after the 2018 experimental campaign [25]. Optical microscopy on the LE of PFU \#12 MB25 (see Figure 4) shows a partially melted edge. The penetration of the magnetic field lines into the poloidal gaps can be inferred by assessing the damaged depth on the side face of the MB. Damage extension of up to $0.79 \mathrm{~mm}$ deep into the surface has been measured on this $M B$, consistent with the vertical misalignment measured above $(h=0.79 \mathrm{~mm})$.

\subsection{WEST VHR IR System}

In the LE vicinity, the toroidal temperature profile along the $M B$ top surface strongly peaks with large gradients of order $100^{\circ} \mathrm{C} / \mathrm{mm}$ because of the interaction of the parallel heat flux at near-normal incidence on a tiny surface. A VHR IR system has been specially developed at WEST to monitor the temperature on and around LEs [22]. The VHR system has a field of view (FoV) covering $2 \times 4 \mathrm{MBs}(64 \times 51 \mathrm{~mm})$. The system has been equipped with two orientable mirrors to be able to cover a wide surface of the divertor $\left(\sim 10^{\circ}\right.$ in the toroidal direction, corresponding to the area where ITER like PFU are installed, from PFU \#6 to PFU \#19) and the 2 strike point areas along the PFU in the poloidal direction (as shown in Figure 3). The pixel size $(0.109 \mathrm{~mm})$ has been measured using an image taken during a disruption where it is possible to scale by the known MB poloidal length $(12 \pm 0.05 \mathrm{~mm})$. When comparing synthetic and experimental data, the submillimeter resolution of the system revealed that the gap between MB27 of PFU \#11 and PFU \#12 of $0.9 \mathrm{~mm}$ wide instead of the nominal $0.5 \mathrm{~mm}$, which was confirmed by the metrological scan (see section 4.4). The optical system has a small 
aperture ( $F / 9)$ and is diffraction limited. The transfer function of the IR system including blurring effects (optical diffraction, optical aberrations, and spatial sampling) can be modelled by a Gaussian function characterized by a standard deviation $\sigma$ [22]. The standard deviation of the VHR system has been computed with an optical ray-tracing code (ZEMAX) and it is found to be $\sigma=0.3 \mathrm{~mm}$ for a mean pixel size of $0.1 \mathrm{~mm}$.

The system was operational for the C3 experimental campaign with a small wavelength infrared (SWIR) filter featuring a 1.6 to $2.1 \mu \mathrm{m}$ bandwidth to take advantage of the dynamics of the signal for the black body temperature range $\left(370\right.$ to $\left.3600^{\circ} \mathrm{C}\right)$, resulting in better accuracy on high temperature and lower sensitivity to emissivity variations. On the other hand, this also implies that the black-body temperature detection threshold ( $T_{\text {threshold, } \mathrm{BB}}$ $\approx 370^{\circ} \mathrm{C}$ ) is high for this system, to obtain a signal-to-noise ratio high enough to analyze IR data.

A value of the $W$ emissivity is required to assess the true surface temperature of the component from the black body temperature. Hence, the emissivity of the bulk tungsten was measured in the laboratory up to $800^{\circ} \mathrm{C}$ with the VHR SWIR filter for pristine $\left(\varepsilon_{w}=0.3\right)$ and damaged $\left(\varepsilon_{w}=0.6\right)$ bulk tungsten samples [26]. Damaged samples were provided by the high heat flux (HHF) JUDITH 2 facility [27] using an electron beam in order to mimic long term damage produced by plasma exposure such as increased roughness and crack network formation.

To transform black body temperature to true experimental temperature ( $\left.T_{\text {exp }}\right)$, Planck's law is used to obtain the corresponding black body (eq. 1) and metallic spectral radiance for a given emissivity (eq. 2):

$$
\begin{gathered}
L_{\lambda}^{B B}\left(T_{B B}\right)=\int_{\lambda \min }^{\lambda \max } \frac{2 h_{p} c^{2}}{\lambda^{5}} \frac{1}{e^{\left(h_{p} c / \lambda k T_{B B}\right)}-1} \mathrm{~d} \lambda \\
L^{W}=L^{B B} \times \varepsilon_{W}+\left(1-\varepsilon_{W}\right) \times L^{a m b}
\end{gathered}
$$

with $L_{\lambda}^{B B}\left(\mathrm{~W} \cdot \mathrm{m}^{-2} \cdot \mathrm{str}^{-1}\right)$ the spectral radiance of the black body, $\mathrm{L}^{\mathrm{W}}\left(\mathrm{W} \cdot \mathrm{m}^{-2} \cdot \mathrm{str}^{-1}\right)$ the spectral radiance of the $\mathrm{W}, \mathrm{L}^{\mathrm{amb}}\left(\mathrm{W} \cdot \mathrm{m}^{-2} \cdot \mathrm{str}^{-1}\right)$ the spectral radiance of the actively cooled ambient environment $\left(T_{a m b}=70^{\circ} \mathrm{C}\right), \lambda$ the wavelength of the filter in the range from $1.6 \times 10^{-6} \mathrm{~m}$ to $2.1 \times 10^{-6} \mathrm{~m}, h_{p}$ Plancks constant, $c$ the speed of light), $k$ the Boltzmann constant, $T$ the temperature of the black body $(\mathrm{K})$ and $\varepsilon_{\mathrm{W}}$ the $\mathrm{W}$ emissivity. 
The correspondence between black body and true surface temperature is given in Figure 5 for low $\left(\varepsilon_{\mathrm{w}}=0.3\right.$, pristine $\left.\mathrm{W}\right)$ and high emissivity $\left(\varepsilon_{\mathrm{w}}=0.6\right.$, damaged $\left.\mathrm{W}\right)$. The true temperature threshold lies therefore in the range of $395^{\circ} \mathrm{C}\left(\varepsilon_{\mathrm{w}}=0.6\right)$ to $435^{\circ} \mathrm{C}\left(\varepsilon_{\mathrm{w}}=0.3\right)$.

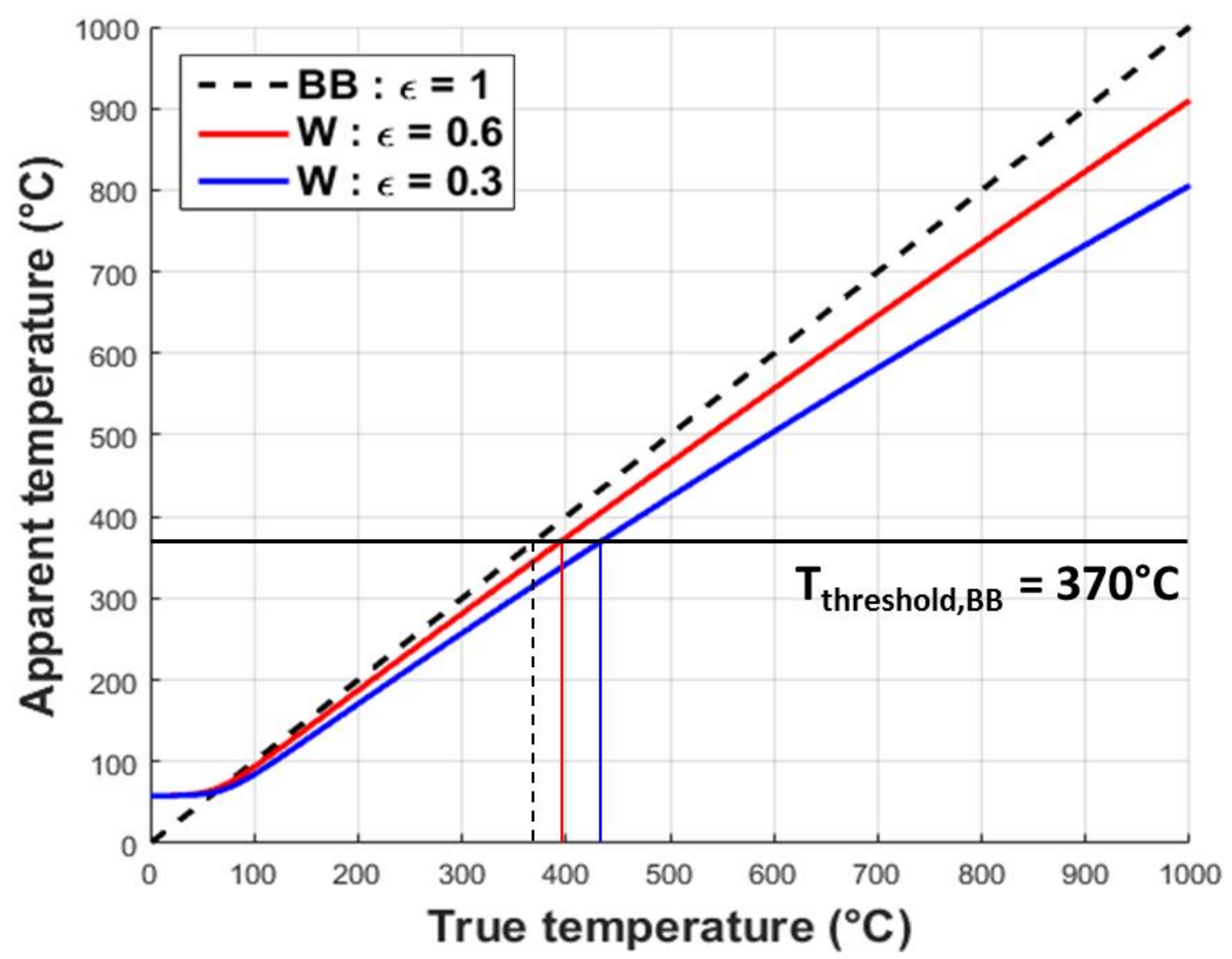

Figure 5. Planck's curves show the black body temperature as a function of the true temperature for a black body $\left(\varepsilon=1-\right.$ dashed black), crack network bulk W $\left(\varepsilon_{\mathrm{w}}=0.6-\mathrm{red}\right)$ and pristine bulk $\mathrm{W}\left(\varepsilon_{\mathrm{w}}=0.3-\right.$ blue) based on eq. 2. The black-body temperature detection threshold is represented here $\left(T_{\text {threshold, } B \mathrm{~B}}=370^{\circ} \mathrm{C}\right)$ while true temperature detection thresholds are plotted in vertical lines as function of this emissivity: $\mathrm{T}_{\text {threshold, } 0.6}=395^{\circ} \mathrm{C}$ (red) and $\mathrm{T}_{\text {threshold }, 0.3}=435^{\circ} \mathrm{C}$ (blue). Apparent temperature is clamped at $70^{\circ} \mathrm{C}$ for real temperature lower than $\mathrm{T}_{\text {amb. }}$. This is due to cavity effect, where the ambient is radiating a black body temperature of $70^{\circ} \mathrm{C}$, covering the signal of the apparent temperature of the body lower than $70^{\circ} \mathrm{C}$.

\subsection{Test of ITER-like PFUs and their shaping}

To study the impact of shaping and misalignment on the thermal behavior of the divertor components, a dedicated experiment was performed in WEST. The aim of the experiment was to achieve high and stationary heat flux for at least $4 \mathrm{~s}$ to reach thermal equilibrium in the $M B$ (the theoretical time constant to reach $95 \%$ of the heating equilibrium is $3.7 \pm 0.1 \mathrm{~s}$ ). Each pulse is repeated three times in order to move the FoV of the VHR IR camera in the three regions of interest already identified: PFU \#7 ( $\mathrm{h}=0.31 \mathrm{~mm}$ - Chamfered), PFU \#12 ( $\mathrm{h}=0.79 \mathrm{~mm}$ - Sharp) and PFU \#19 ( $\mathrm{h}=0.63 \mathrm{~mm}$ - Chamfered). The experiment shows that 
the VHR detects local hot spots properly above $4 \mathrm{MW}$ of injected power in the far X-point (FXP) magnetic configuration (with the X-point $90 \mathrm{~mm}$ above the target) which minimizes the magnetic flux expansion and maximizes the target heat flux. The data presented here will focus on the FXP magnetic configuration with maximum injected $\mathrm{LH}$ power $\mathrm{P}_{\text {inj }}=4.6 \mathrm{MW}$ and outer strike point located on MB\#27. Plasma parameters are: plasma current $I_{p}=500 \mathrm{kA}$, and magnetic field $\mathrm{B}_{\mathrm{T}}=3.6 \mathrm{~T}$. Line-averaged density, $\bar{n}_{e}$ is shown to vary slightly during the $\mathrm{LH}$ heating phase, in the range of 3.4 to $3.7 \times 10^{19} \mathrm{~m}^{-2}$. Although $\bar{n}_{e}$ is not perfectly reproduced from shot to shot, the variation is limited to $0.2 \times 10^{19} \mathrm{~m}^{-2}$. The radiated power fraction is in the range of $f_{\text {rad }} \sim 55 \%$. Injected and radiated power are shown in Figure 6 for the three selected shots.
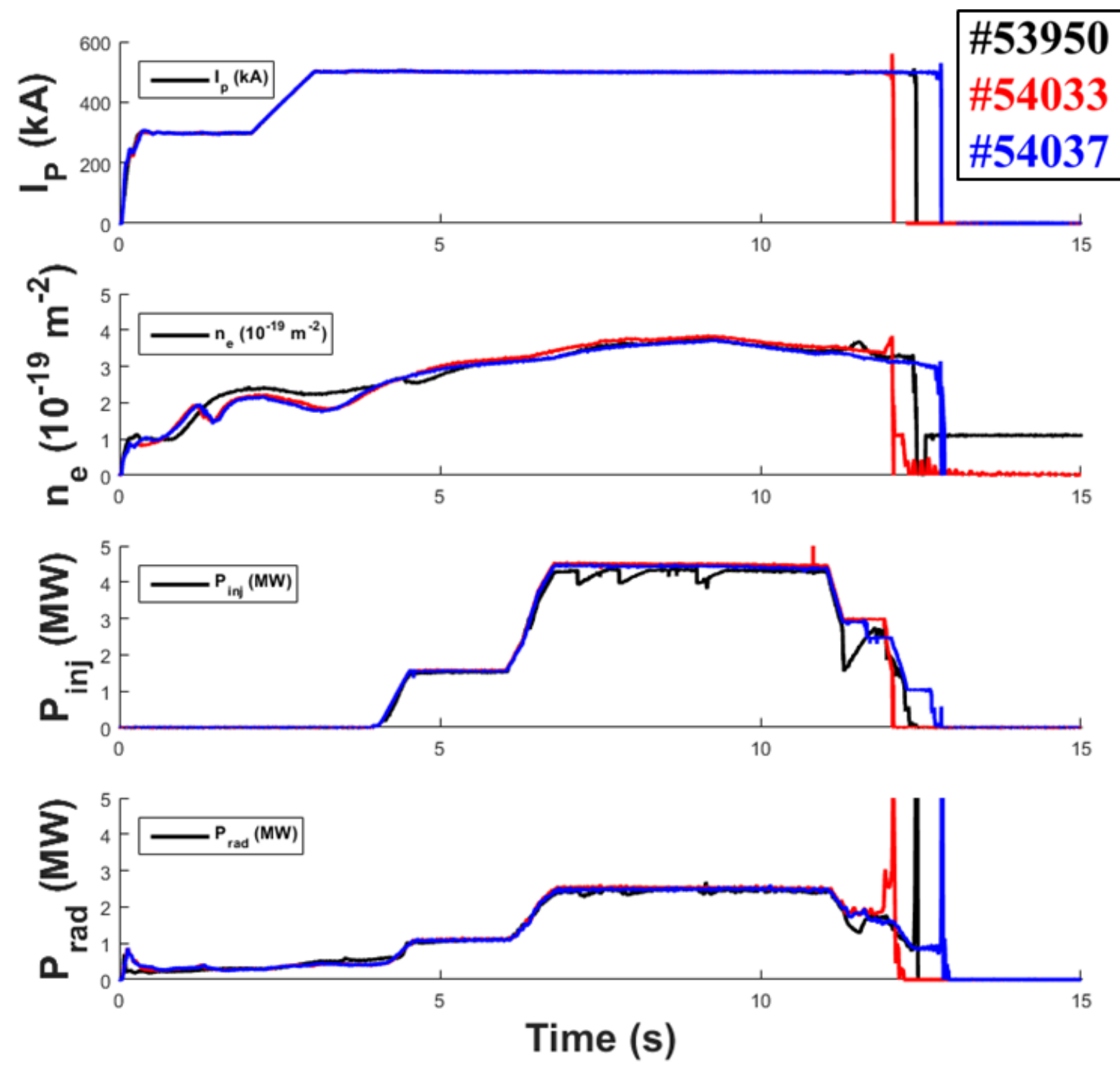

Figure 6. Plasma characteristics of shots \#53950 (black), \#54033 (red) and \#54037 (blue) showing repeatability of the shot on plasma current (kA), line average density $\left(10^{19} \mathrm{~m}^{-2}\right)$ and on injected and radiated power (MW). 
Shots \#54033 and 54037 are very similar as they have been performed with the same inputs and same plasma conditions. Shot \#53950 has slightly lower injected power and three short reductions of power provoked by the real-time copper impurity safety interlock system. The power received on the divertor is computed as follows:

$$
P_{\text {div }}=P_{\text {inj }}+P_{\text {ohm }}-P_{\text {rad }}-P_{\text {LH-losses }}
$$

$\mathrm{P}_{\text {div }}$ being the power received by the divertor $(\mathrm{MW}), \mathrm{P}_{\text {inj }}$ the power injected with RF heating $(\mathrm{MW}), \mathrm{P}_{\mathrm{ohm}}$ the ohmic power (MW), Prad the radiated power (MW) measured by bolometry, and $\mathrm{P}_{\mathrm{LH} \text {-losses }}$ the power deposited by vertically-drifting electrons trapped in the magnetic field ripple on the upper part of the machine, estimated with calorimetry.

\section{$4 \quad$ IR data processing and heat flux calculation}

\subsection{Plasma heat load characteristics}

The heat flux on the top (eq.4) and side (eq.5) surface of a leading edge is computed with the optical approximation (OA):

$$
\begin{gathered}
q_{t o p}=q_{\|} \sin \alpha+q_{B G} \\
q_{s}=q_{\|} \sin (\alpha+\beta)
\end{gathered}
$$

where $\alpha$ is the field line angle which is derived from the magnetic equilibrium and CAD model of the divertor (PFCFlux software [28]), $\beta$ being the angle between the top and poloidal-side surface $(\pi / 2$ for a sharp edge and $\pi / 4$ for a $1 \times 1 \mathrm{~mm}$ chamfer edge), $q / /$ the heat flux density parallel to $B, q_{\text {top }}$ and $q_{s}$ respectively the heat flux densities absorbed on top and side surfaces. $\mathrm{q}_{\mathrm{BG}}$ represents the background heat flux (including plasma radiation and neutral particles coming from charge exchange) which is supposed here to be homogeneous for simplification. To first approximation, the heat load is assumed to be uniform in the poloidal direction (with no plasma shape parameters such as the heat flux decay length or the spreading factor [29]). Due to the high temperature detection threshold of the VHR, the full surface of the MB cannot be studied, hence it is impossible here to determine the $\mathrm{q}_{\mathrm{BG}}$ value.

The wetted height of the leading edge $\left(h_{w}\right)$ which is directly exposed to the plasma heat flux depends on the misalignment of the component $(\mathrm{h})$, the gap between the two consecutive PFUs ( $g_{P F U}$ ), as well as the incidence angle at the strike point location for both sharp and chamfered geometries (see Figure 7) 


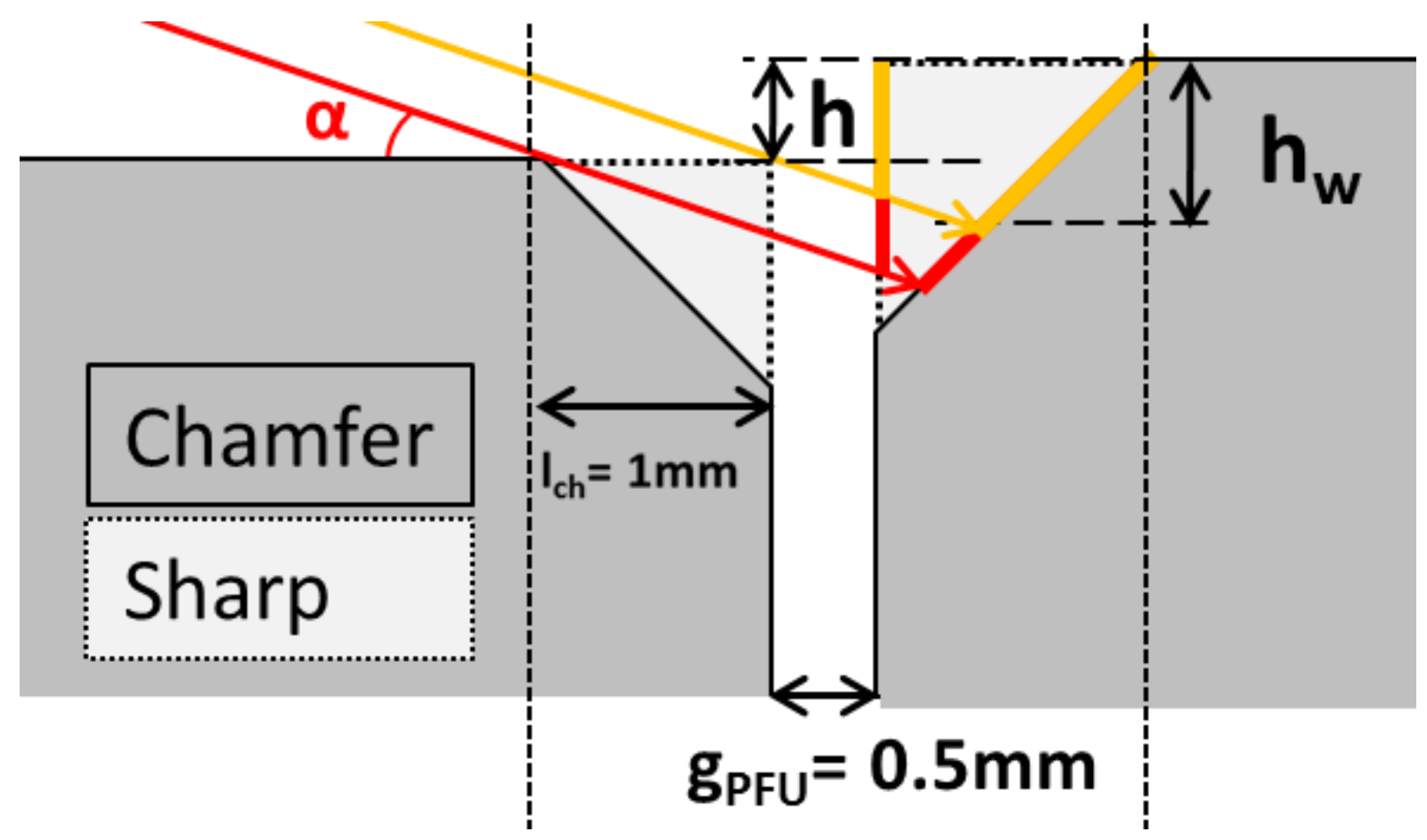

Figure 7. The wetted area on the side of a MB misaligned with its neighbor is represented in this picture for a chamfer (lines) and a sharp edge (dashed lines) shaping. The deepest magnetic field line striking the MB is shown whether the neighbor has a chamfered (red) or sharp trailing edge (orange). The wetted area is characterized by its height $\left(h_{w}\right)$.

$I_{C h}$ being the length of a chamfer $(1 \mathrm{~mm})$. The exposed height of the leading edge has been calculated for PFU \#7 ( $\left.h_{w}=0.40 \mathrm{~mm}\right)$ PFU \#12 $\left(h_{w}=0.84 \mathrm{~mm}\right)$ and PFU \#19 $\left(h_{w}=0.65 \mathrm{~mm}\right)$.

\subsection{Thermal modelling and synthetic data processing $\left(\boldsymbol{T}_{\text {synth }}\right)$}

The thermal modelling is performed with a 3D finite element method (FEM - ANSYS software). The calculation is made on ITER-like MB prototypes with $28 \mathrm{~mm}$ width (ITER standard width for thermal calculation) and $6 \mathrm{~mm}$ tungsten thickness between the top surface and the CuOFHC joint covering the $\mathrm{CuCrZr}$ cooling tube in steady state. The ITER-like MB dimensions are shown on the left panel of Figure 8. 


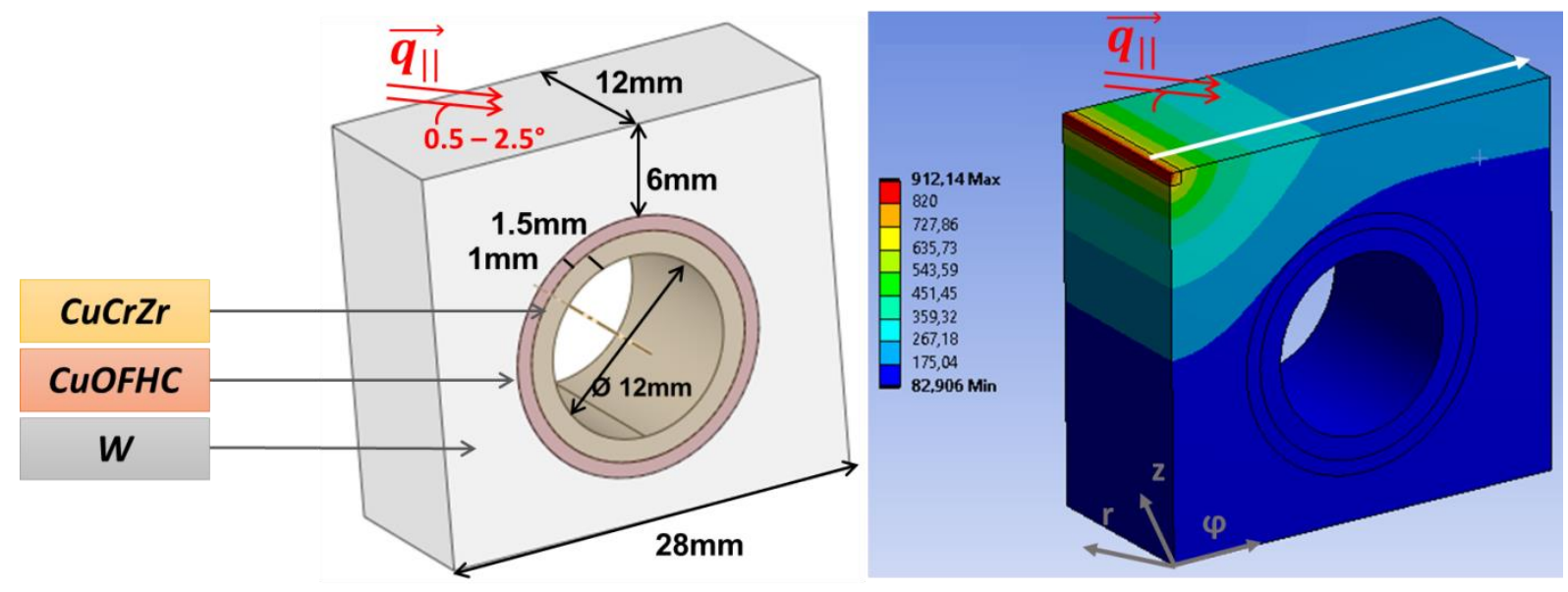

Figure 8. WEST ITER-like MB front view showing the dimensions and materials of the MB (left). Thermal modelling performed for parallel heat flux $\mathrm{q} / /=43 \mathrm{MW} \cdot \mathrm{m}^{-2}$, plasma exposure height calculated for incidence angle $\alpha=1.9^{\circ}$ and misalignment $h=0.793 \mathrm{~mm}\left(h_{w}=0.84 \mathrm{~mm}\right.$ on PFU12 sharp leading edge). A net local heating appears on the sharp edge exposed to plasma shown in red arrows. The white arrow corresponds to the toroidal path shown later in the analysis (right).

The thermal modelling gives the spatial distribution of the surface temperature ( $\left.T_{F E M}\right)$ that is used later to derive the synthetic temperature ( $\left.T_{\text {synth }}\right)$ as seen by the VHR IR system. An example of thermal modelling is shown in the right panel of the Figure 8 for one case described in the next section (PFU12 sharp leading edge).

Despite a very high spatial resolution (pixel size $=0.109 \mathrm{~mm}$ ), the pixel size and MTF of the IR system have to be taken into account given the very steep temperature gradient near the LE. A specific sensor correction has been developed [12] to simulate the pixel size, optical blurring and deformation. The numerical radiance profile (calculated from TFEM) is convoluted with the transfer function of the instrument which is modelled by a Gaussian in frequency space with a standard deviation $(\sigma)$ of $0.3 \mathrm{~mm}$. The sensor correction takes also into account the thermal pattern around the misaligned $\mathrm{MB}$, including gap and adjacent $\mathrm{MB}$. Modelled and synthetic IR data are presented in Figure 9 for the same case as depicted before (PFU12 sharp leading edge). 


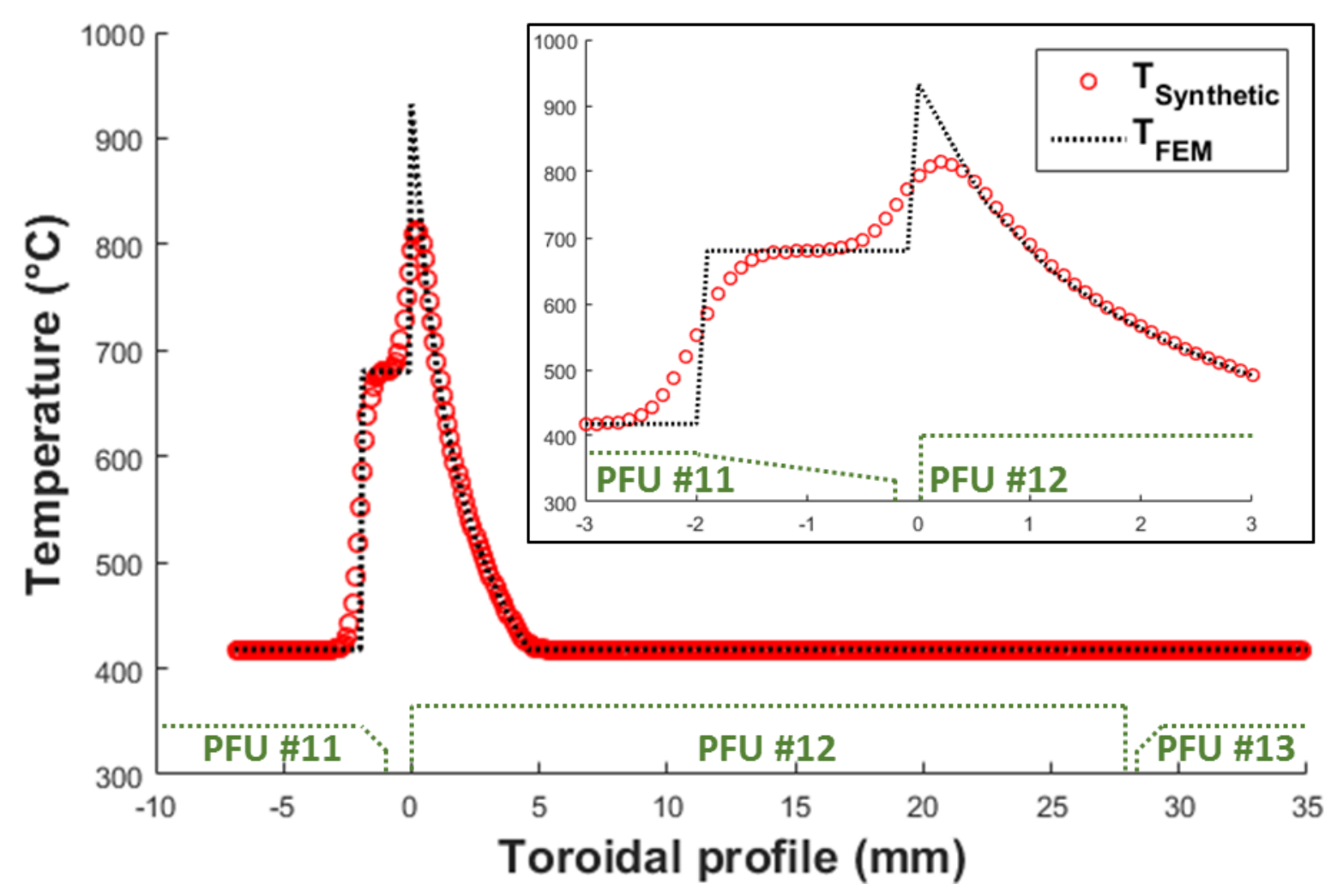

Figure 9. Sensor correction applied for a toroidal temperature profile on PFU \#12 (sharp leading edge). The black dashed line represents the temperature distribution obtained by thermal modelling on PFU\#12 and completed by the thermal pattern to describe the previous PFU (\#11 chamfered). The red circles represent the synthetic temperature data using a pixel size of $0.109 \mathrm{~mm}$, a standard deviation $\sigma=0.3 \mathrm{~mm}$ for the instrument transfer function, and the SWIR filter $(1.7 \mu \mathrm{m})$. Green dashed lines represent the geometry of the thermal pattern. The inset shows the leading edge area in more detail.

The inset shows how the smoothing effect reduces the maximum apparent temperature on the leading edge from the real value of $916^{\circ} \mathrm{C}$ to $814^{\circ} \mathrm{C}$ as measured by the instrument, a decrease of $\sim 100^{\circ} \mathrm{C}(\sim 11 \%)$. Moreover, the maximum temperature measured on the synthetic profile is located $0.2 \mathrm{~mm}$ away from the leading edge.

\subsection{IR data processing}

For the preliminary experiments analyzed in this paper, the analysis is focused on the overexposed LEs and their vicinity (over a distance of a few $\mathrm{mm}$ ), in the temperature range where the VHR IR camera is operational (above $400^{\circ} \mathrm{C}$ ). This represents a few tens of pixels which is enough to obtain a part of the temperature decay in the toroidal direction and calculate the heat flux deposited on the side surface of the MB. 
An iterative method is applied to find the parallel heat flux that matches experimental data in terms of maximum temperature and decay along the MB. Calculation through FEM has been performed to match with experimental data for the two extreme emissivity values that have been obtained in laboratory 0.3 (pristine $W$ ) and 0.6 (damaged $W$ ) [26]. After the C3 experiments, the MB surface evolution was investigated by optical microscopy [25]. On the misaligned PFU, the MB surfaces exhibit surface damage (cracking) on the leading edge as well as a thin band on the top surface, at the leading edge vicinity. Regarding these results, a high emissivity is expected near the leading edge.

Three cases are presented in the next section, PFU \#7, PFU \#12, and PFU \#19. The pixel size is set to $r=0.109 \mathrm{~mm}, \varepsilon_{\mathrm{w}}=0.6$ (damaged surface) and uniform plasma heat flux at the target. Results assuming lower emissivity $\left(\varepsilon_{\mathrm{w}}=0.3\right)$ will be discussed in Section 5 .

\subsection{Comparison between experimental and synthetic temperature:}

PFU \#7 is located at the location of maximum surface heat flux with respect to the toroidal ripple effect (see Figure 2). The incidence angle of the magnetic field is $2.6^{\circ}$ and the chamfered leading edge misalignment is $0.31 \mathrm{~mm}$. The parallel heat flux is adjusted to match the temperature profile on the first $2 \mathrm{~mm}$ of the flat top part of the MB where the temperature is higher than detection threshold (see right panel of the Figure 10). The best match between synthetic and experimental IR data is obtained with $\mathrm{q} / /=41 \mathrm{MW} \cdot \mathrm{m}^{-2}$. The average difference between modeling and IR data is $6^{\circ} \mathrm{C}$ along the profile. The maximum temperature given by the FEM calculation is $487^{\circ} \mathrm{C}$ on the chamfered LE while the measurement gives $465^{\circ} \mathrm{C}$ due to the finite spatial resolution effect.
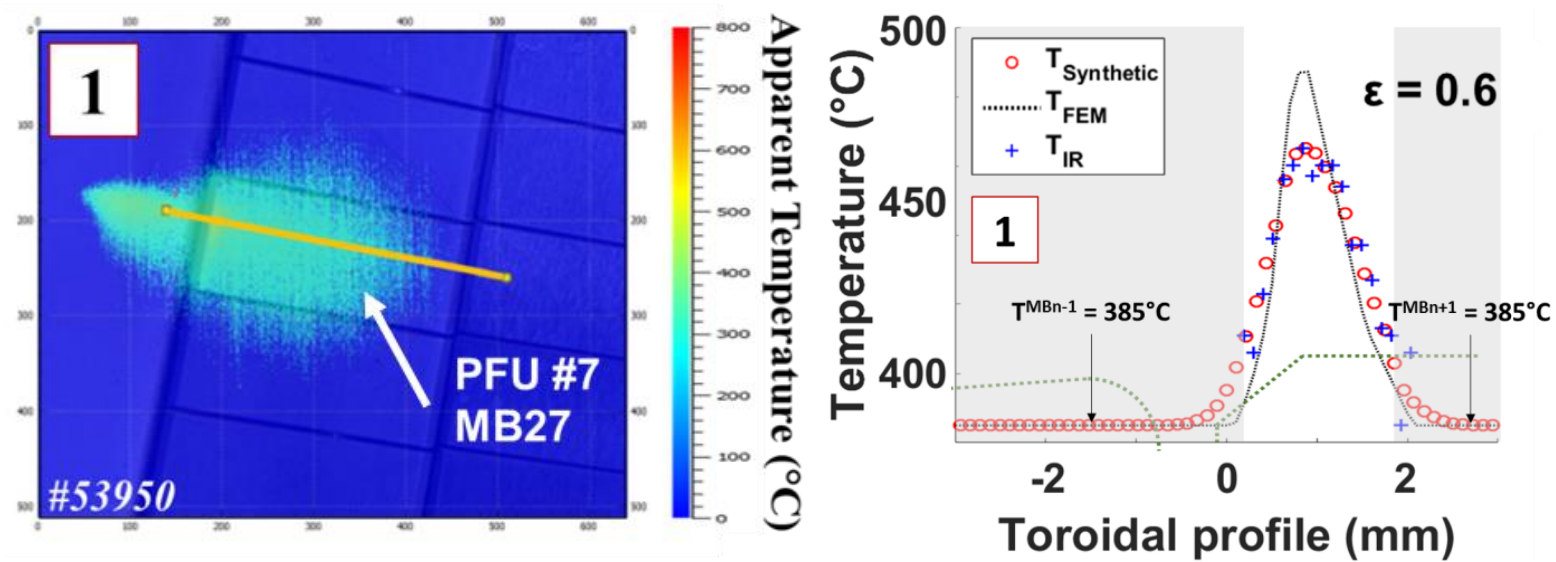

Figure 10. Shot \#53950 on PFU \#7 (chamfered edge $-\mathrm{h}=0.31 \mathrm{~mm}$ ). Left: an IR data frame with SWIR filter (1.7 $\mu \mathrm{m}$ ) exhibits local heating on MB27. The IR detection threshold being high, it is necessary to superimpose a photograph of the real geometry to detect the ITER-like MBs. Right: comparison between experimental IR (blue 
corrected with $\varepsilon_{w}=0.6$ ) and synthetic temperature (red) based on thermal modelling (dark) of the toroidal profile. Shadowed parts exhibit the area where the IR temperature measurement is not reliable.

PFU \#12 exhibits a sharp leading edge and a high misalignment $(0.79 \mathrm{~mm})$ with the previous PFU. It is located between the minimum and maximum surface heat flux regions, where the incidence angle is $1.9^{\circ}$ (see Figure 2). Because of the high misalignment and sharp geometry, the surface temperatures measured in this pulse are higher than the previous one (see left panel Figure 11). As a consequence the temperature profiles are extended from $-3 \mathrm{~mm}$ up to $+3 \mathrm{~mm}$ around the LE (see right panel Figure 11). The thermal pattern becomes more complex and can be divided in two parts.

From $-3 \mathrm{~mm}$ to $0 \mathrm{~mm}$ (left part of the right panel in Figure 11), one can see the gap $(0.9 \mathrm{~mm}$ wide), the chamfer which is $1 \mathrm{~mm}$ broad (trailing edge) and a small part of the top surface of PFU \#11. The light emitted from the hot and sharp leading edge of PFU\#12 is reflected on the chamfer of PFU \#11 toward the IR camera detector. As a result, the experimental temperature profile exhibits a shoulder including two temperature steps, first one in the gap, a second one at the line between chamfer and top surface of PFU\#11. In order to mimic the thermal pattern with gap and reflection, a simple model including constant temperature of $680^{\circ} \mathrm{C}$ has been adjusted to match with the temperature in the trailing chamfer $(-2 \mathrm{~mm}$ to $-0.1 \mathrm{~mm}$ scale). The temperature discrepancy observed from $-0.9 \mathrm{~mm}$ and $0.0 \mathrm{~mm}$ corresponds to the gap temperature, which cannot be reproduced using a simple constant temperature. The physics of the temperature measurement in a gap would need to be further investigated, but this is outside the scope of this paper. The second temperature step occurs between the chamfered $\left(680^{\circ} \mathrm{C}\right)$ and the top surface of PFU\#11 (below the IR temperature threshold). The good match between experimental and synthetic data in steep temperature difference area validates the modelling of the transfer function computed with the optical ray tracing code $(\sigma=0.3 \mathrm{~mm}$, see 2.2).

Observing the profile from $0 \mathrm{~mm}$ to $3 \mathrm{~mm}$, one can see the thermal decay associated with the overexposed sharp leading edge of PFU\#12. The best match between synthetic and experimental IR data is obtained with parallel heat flux of $43 \mathrm{MW} \cdot \mathrm{m}^{-2}$. The average difference between FEM modeling and IR data is $15^{\circ} \mathrm{C}$. The maximum temperature computed with FEM is $910^{\circ} \mathrm{C}$ on the sharp leading edge while the measurement gives $800^{\circ} \mathrm{C}$ due to the instrumental effect. 

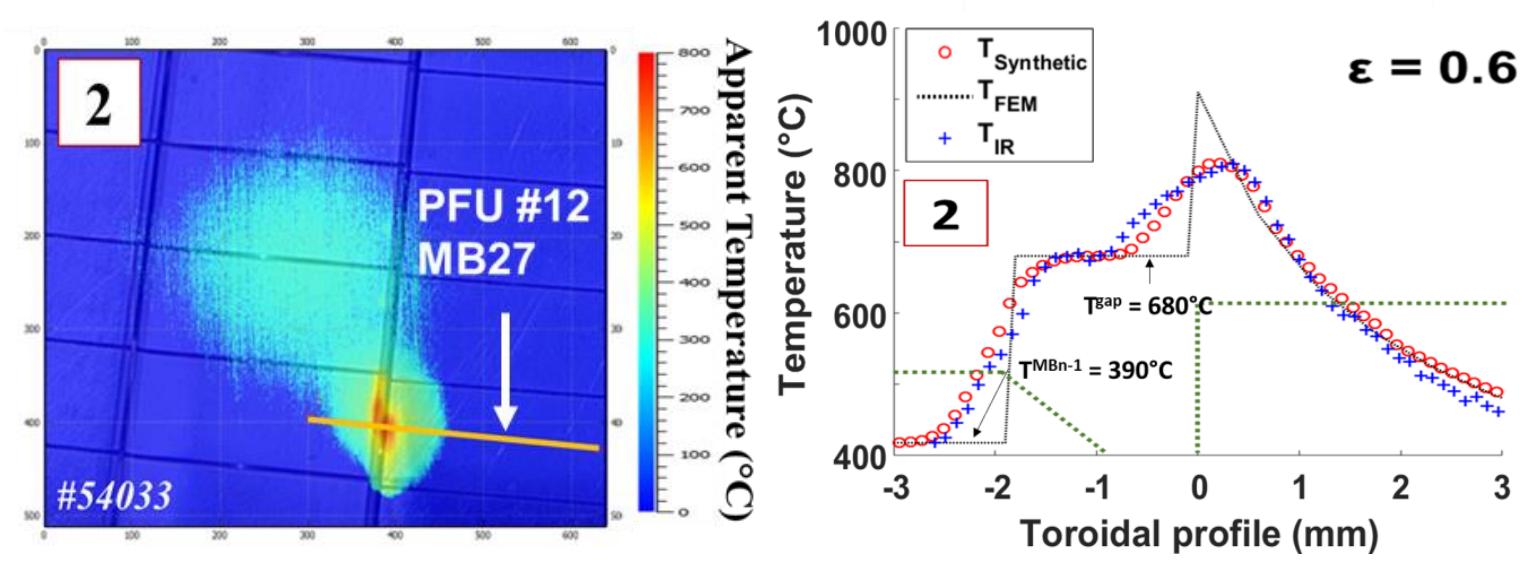

Figure 11. Analogous to Figure 10 for shot $\# 54033$ on PFU \#12 (sharp edge $-\mathrm{h}=0.79 \mathrm{~mm}$ ). .

PFU \#19 exhibits a chamfered LE with a high misalignment ( $h=0.63 \mathrm{~mm}$ ) with the previous PFU. It is located at the minimum surface heat flux due to the toroidal ripple effect (see Figure 2). The incidence angle is grazing $\left(0.6^{\circ}\right)$ and the heat flux on top surface is therefore very small. On the chamfered surface, the incident angle is close to $45^{\circ}$, hence the surface temperature measurement is lower $\left(550^{\circ} \mathrm{C}\right.$ assuming $\left.\varepsilon_{\mathrm{w}}=0.6\right)$ than reported on the sharp leading edge $\left(820^{\circ} \mathrm{C}\right.$ assuming $\left.\varepsilon_{\mathrm{w}}=0.6\right)$ with an incident angle almost normal to the surface. In addition, the exposed LE is not centered in the FoV and subject to vignetting effect (transmission of the system is degraded compared to the center of the FoV). As a consequence, the temperature drops rapidly below the detection threshold (if the signal received by some pixels is under the offset of the camera, then the data acquisition system returns automatically $0^{\circ} \mathrm{C}$ for these pixels). As for PFU\#07, the working area is limited to $2 \mathrm{~mm}$ around the overexposed chamfered MB.

The best match between synthetic and experimental IR data is obtained with a parallel heat flux of $48 \mathrm{MW} \cdot \mathrm{m}^{-2}$, which is slightly higher than the two previous cases. The average difference is $9^{\circ} \mathrm{C}$ along the profile (see Figure 12). The maximum temperature calculated is $580^{\circ} \mathrm{C}$ on the chamfered leading edge while the measurement is $550^{\circ} \mathrm{C}$. 

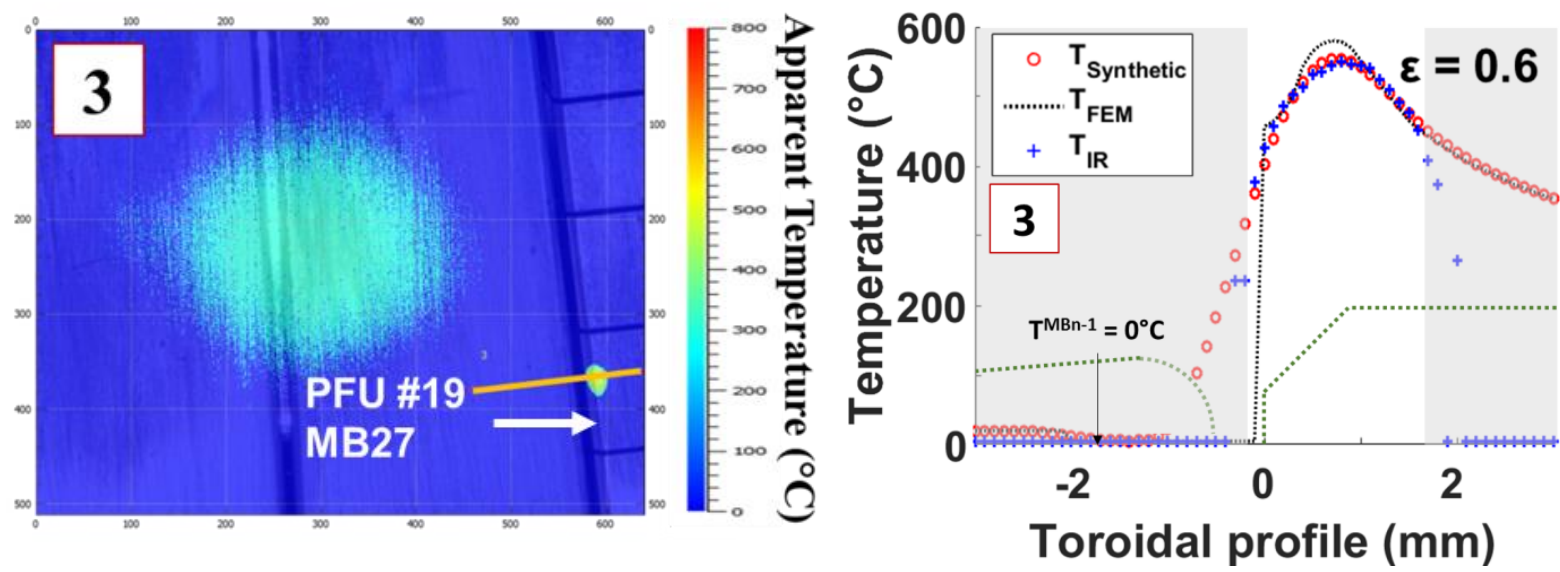

Figure 12. Analogous to Figure 10 for Shot \#54037 on PFU \#19 (chamfer edge $-\mathrm{h}=0.63 \mathrm{~mm}$ ).

\section{$5 \quad$ Summary of the results and discussion}

As seen in the previous section, a quantitative match has been obtained between synthetic and experimental data for each of the three FoV -assuming high emissivity $\varepsilon_{\mathrm{w}}=0.6-$ with chamfered or sharp edges at different toroidal positions.

A sensitivity study has been performed to assess the impact of the $W$ emissivity assumed. Parallel heat flux estimates for the VHR system assuming emissivity being 0.3 (pristine W) or 0.6 (damaged $\mathrm{W}$ ) are reported in the table below together with those given by the FBG diagnostic. The discrepancy in the evaluation of the parallel heat flux attributed to the emissivity uncertainty (between 0.3 and 0.6 ) is found to be $<15 \%$.

\begin{tabular}{|c|c|c|c|c|}
\hline \multirow{3}{*}{ Shot } & $\mathbf{P}_{\text {div }}(\mathbf{M W})$ & \multicolumn{3}{|c|}{ Parallel heat flux estimation on the divertor $\left(\mathrm{MW} \cdot \mathrm{m}^{-2}\right) / / \mathrm{q}_{/ /}$per MW received on divertor } \\
\hline & \multirow{2}{*}{$P_{\text {inj }}+P_{\text {Ohm }}-P_{\text {rad }}-P_{\text {LH-losses }}$} & \multicolumn{2}{|c|}{ THR } & \multirow{2}{*}{$\begin{array}{c}\text { FBG } \\
\bar{\alpha} \\
\end{array}$} \\
\hline & & $\varepsilon=0,6$ & $\varepsilon=0,3$ & \\
\hline $53950-P F U 7-2.6^{\circ}$ & 1.61 & $41 / / 25.4$ & $46 / / 28.6$ & $35.7 \pm 3.2 / / 21.5 \pm 3.0$ \\
\hline $54033-\mathrm{PFU} 12-1.9^{\circ}$ & 1.77 & $43 / / 24.2$ & $50 / / 28.2$ & $44.2 \pm 4.6 / / 24.8 \pm 3.4$ \\
\hline 54037 - PFU19 - $0.6^{\circ}$ & 1.71 & $48 / / 28.1$ & $53 / / 31.0$ & $44.2 \pm 3.9 / / 25.5 \pm 3.5$ \\
\hline
\end{tabular}

Table 2. Parallel heat flux measurements (black) obtained with the VHR IR (emissivity 0.3 \& 0.6), and FBG for the three reproducible shots (\#53950, \#54033 \& \#54037) with the VHR IR system focusing on three different overexposed leading edges (respectively PFU \#7 PFU \#12 \& PFU \#19). Parallel heat flux calculation normalized to the power incident on the divertor (blue) has been reported for a better comparison on the toroidal symmetry of the parallel heat flux.

Moreover, results derived from the VHR IR data have been compared to independent measurements from the FBG. These are embedded thermal sensors with a $12.5 \mathrm{~mm}$ spatial resolution in the poloidal direction implemented with $3.5 \mathrm{~mm}$ and $7.0 \mathrm{~mm}$ depths [23]. FBGs are immune to electromagnetic interference and independent of $W$ surface emissivity. Surface heat flux calculations ( $q_{t o p}$ ) were performed for each pulse as described in [30]. Since the FBG provides the heat flux absorbed on the top surface $\left(q_{t o p}\right)$, the incidence angle is required to obtain the parallel heat flux using equation (4). FBG estimations are performed in inertial W-coated graphite PFUs located in the maximum heat flux area (equivalent to PFU 7 
as shown in Figure 2), where the angle is $3.3 \pm 0.13^{\circ}$. With such an angle, a small uncertainty of about $0.2^{\circ}$, can change the parallel heat flux by $5 \%$. The VHR IR measurements, inferred from a LE loading at a near perpendicular incidence, are less sensitive to the incidence angle because the incidence angle is larger on the side of the LE (slightly above $90^{\circ}$ and $45^{\circ}$ for a sharp and chamfered LE respectively).

Parallel heat fluxes estimated with $\varepsilon_{\mathrm{w}}=0.6$ are closer to reference values given by FBG measurements ( 0 to $15 \%$ discrepancy) than that estimated with $\varepsilon_{w}=0.3$ (10 to $35 \%$ discrepancy). This is consistent with the post-mortem visual inspection which reveals some damage on the top surface near the LE.

While the ripple effect modulates the top surface heat flux on the divertor, the OSP parallel heat flux derived from the VHR IR measurements at various PFU toroidal locations is constant. This has been checked in the database studied here, normalizing the OSP parallel heat flux derived from the VHR IR by the power received by the divertor to account for discrepancies between shots (see table 2, blue values). The VHR measurements give a mean value of $26 \mathrm{MW} \cdot \mathrm{m}^{-2} / \mathrm{MW}_{\text {div }}$ with $8 \%$ discrepancy in the toroidal direction. This value is nearly constant for all the PFU geometries, misalignments and toroidal positions considered here, as expected. Moreover, it is very close to the mean value obtained with the FBG system of $24 \pm 2 \mathrm{MW} \cdot \mathrm{m}^{-2} / \mathrm{MW}_{\text {div }}$. This gives confidence in the VHR IR data processing described here.

The validity of the OA has also been checked. For the experiments depicted above, the electron density and temperature in the outer divertor are measured with Langmuir probes: $\mathrm{n}_{\mathrm{e}} \sim 3.5 \times 10^{19} \mathrm{~m}^{-3}$ and $\mathrm{T}_{\mathrm{e}} \sim 30 \mathrm{eV}$. For such plasma conditions and $\mathrm{B}_{\mathrm{t}}=3.6 \mathrm{~T}$, the deuterium and electron Larmor radii are respectively $r_{L i}=0.3 \mathrm{~mm}$ (assuming $T_{e}=T_{i}$ ) and $r_{L e}=5 \mu m$. Particle-incell (PIC) simulations show that the power deposition profile around a LE generally differs from the OA when the height of the misalignment is smaller than two Larmor radii, i.e. $h<2 r_{L}$ [31]. Hence, the $O A$ is expected to be valid for electrons, while for ions, the ion Larmor radii should impact the heat flux distribution on chamfered PFUs (h $\leq 0.6 \mathrm{~mm}$ ). It was not possible to observe this effect with the VHR IR due to the high temperature detection threshold limiting the analysis to the LE vicinity.

Extrapolation from present data to higher incident flux has been performed, in order to assess possible limitations of the operational domain for the next WEST campaigns. For the experiments analyzed in this study, the temperature reached $910^{\circ} \mathrm{C}$ on the most misaligned sharp LE (PFU \#12 - $\mathrm{h}=0.79 \mathrm{~mm}$ ). The IR analysis indicates that the temperature obtained during the experiments was not high enough to reach recrystallization $\left(T=1200^{\circ} \mathrm{C}\right)$ or melting $\left(\mathrm{T}=3400^{\circ} \mathrm{C}\right)$. As a first indication, a simple extrapolation on PFU \#12 would predict that $\mathrm{W}$ recrystallization and melting temperature would be obtained for parallel heat fluxes of 
$55 \mathrm{MW} \cdot \mathrm{m}^{-2}$ and $140 \mathrm{MW} \cdot \mathrm{m}^{-2}$ respectively. This would correspond to a limit around $2.5 \mathrm{MW} \cdot \mathrm{m}^{-}$ 2 and $6 \mathrm{MW} \cdot \mathrm{m}^{-2}\left(\alpha \sim 2.5^{\circ}\right)$ on the top surface of the W MBs. The components have therefore been re-aligned within ITER tolerances $(h<0.3 \mathrm{~mm}$ ) for the next experimental campaign (C4) where higher heat fluxes are expected.

Finally, a comparison between sharp and chamfered PFU LE geometries has been performed, based on steady state FEM calculation for actively cooled ITER-like MBs for the maximum misalignment expected in ITER $(\mathrm{h}=0.3 \mathrm{~mm})$. They are summarized in table 3 , which shows that $\mathrm{W}$ melting temperature is reached for stationary parallel heat fluxes of $225 \mathrm{MW} \cdot \mathrm{m}^{-2}$ for the chamfered and $205 \mathrm{MW} \cdot \mathrm{m}^{-2}$ for sharp geometries (for information, the nominal stationary heat flux of $10 \mathrm{MW} \cdot \mathrm{m}^{-2}$ corresponds to a parallel heat flux $200 \mathrm{MW} \cdot \mathrm{m}^{-2}$ for both ITER and WEST conditions). Using a chamfer instead of a sharp leading edge geometry allows the safety margin on W-melting to be increased by $\sim 10 \%$ for a misalignment of $0.3 \mathrm{~mm}$.

\begin{tabular}{cc|cccc}
\hline & & \multicolumn{4}{|c}{ Parallel heat flux (MW.m ${ }^{-2}$ ) } \\
\hline Geometry & Misalignment $(\mathrm{mm})$ & 50 & 100 & 150 & 200 \\
\hline Chamfer & 0.3 & $680^{\circ} \mathrm{C}$ & $1425^{\circ} \mathrm{C}$ & $2210^{\circ} \mathrm{C}$ & $2990^{\circ} \mathrm{C}$ \\
Sharp & 0.3 & $740^{\circ} \mathrm{C}$ & $1570^{\circ} \mathrm{C}$ & $2435^{\circ} \mathrm{C}$ & $3315^{\circ} \mathrm{C}$ \\
\hline
\end{tabular}

Table 3. Predictions of the maximum temperature on sharp and chamfered leading edges for a misalignment $\mathrm{h}=0.3 \mathrm{~mm}$ (ITER tolerances) with an incidence angle of $3^{\circ}$ (ITER conditions) from $50 \mathrm{MW} \cdot \mathrm{m}^{-2}$ to $200 \mathrm{MW} \cdot \mathrm{m}^{-2}$ parallel heat flux. Green background means temperature under the recrystallization threshold $\left(T=1200^{\circ} \mathrm{C}\right)$ orange means recrystallization but reasonably far from tungsten melting, while red means close to $\mathrm{W}$-melting $\left(\mathrm{T}=3400^{\circ} \mathrm{C}\right)$.

\section{Conclusion}

This paper describes the thermal response of misaligned leading edges of ITER-like PFUs observed for the first time with the very high resolution infrared camera in the WEST tokamak. Three PFUs with various geometries (sharp and chamfered), incidence angle (from $0.6^{\circ}$ to $2.6^{\circ}$ ) and misalignment ( 0.3 to $0.8 \mathrm{~mm}$ ) have been studied. Dedicated experiments have been performed, with repetitive $L$ mode shots at $\sim 4.5 \mathrm{MW}$ of $\mathrm{LH}$ power, moving the FoV of the VHR IR camera to the misaligned PFU of interest on a shot-to-shot basis. The flattop duration at full power was long enough to get close to the thermal steady state of the components. This first study was focused on an area of a 2-3 $\mathrm{mm}$ in the vicinity of the leading edges, where the temperature was above the VHR IR camera detection threshold. The parallel heat flux was derived from the VHR IR measurements, using synthetic temperature modelling to match the experimental data, and compared with an independent measurement from Fiber Bragg Gratings. It is shown that a $W$ emissivity of $\varepsilon_{\mathrm{w}}=0.6$, corresponding to damaged $W$, gives the best match between the VHR IR and the FBG data. The three PFU studied also give consistent results in terms of parallel heat flux, giving confidence in the VHR IR analysis 
performed. A maximum temperature of $910^{\circ} \mathrm{C}$ has been computed for the PFU \#12 having a misaligned sharp leading edge $\left(h=0.79 \mathrm{~mm}\right.$ ) for a parallel heat flux of $45 \mathrm{MW} \cdot \mathrm{m}^{-2}$.

For the following WEST campaign, a new filter - medium wavelength IR (MWIR) 3.9 $\mu \mathrm{m}$ - has been implemented in the VHR IR camera, in order to reduce the temperature detection threshold. This will allow the area which can be analyzed on the PFU leading edge to be extended to lower temperature and is well adapted to monitor the smaller PFU misalignment implemented ( $\mathrm{h}<0.3 \mathrm{~mm}$, consistently with the ITER specifications).

\section{Acknowledgments}

This work has been carried out within the framework of the EUROfusion Consortium and has received funding from the Euratom research and training program 2014-2018 and 2019-2020 under grant agreement No 633053. The views and opinions expressed herein do not necessarily reflect those of the European Commission or the ITER Organization.

This work has been carried out thanks to the support of the A*MIDEX project ( $\mathrm{n}^{\circ}$ ANR-11-IDEX-0001-02) funded by the "Investissements d'Avenir" French Government program, managed by the French National Research Agency (ANR).

\section{References}

[1] F. Escourbiac et al., "Assessment of critical heat flux margins on tungsten monoblocks of the ITER divertor vertical targets," Fusion Engineering and Design, vol. 146, pp. 20362039, Sep. 2019, doi: 10.1016/j.fusengdes.2019.03.094.

[2] R. A. Pitts et al., "Physics basis for the first ITER tungsten divertor," Nuclear Materials and Energy, vol. 20, p. 100696, Aug. 2019, doi: 10.1016/j.nme.2019.100696.

[3] J. P. Gunn et al., "Surface heat loads on the ITER divertor vertical targets," Nucl. Fusion, vol. 57, no. 4, p. 046025, 2017, doi: 10.1088/1741-4326/aa5e2a.

[4] R. A. Pitts et al., "Physics conclusions in support of ITER W divertor monoblock shaping," Nuclear Materials and Energy, vol. 12, pp. 60-74, Aug. 2017, doi: 10.1016/j.nme.2017.03.005.

[5] A. S. Kukushkin et al., "Analysis of performance of the optimized divertor in ITER," Nucl. Fusion, vol. 49, no. 7, p. 075008, May 2009, doi: 10.1088/0029-5515/49/7/075008.

[6] A. S. Kukushkin, H. D. Pacher, V. Kotov, G. W. Pacher, and D. Reiter, "Finalizing the ITER divertor design: The key role of SOLPS modeling," Fusion Engineering and Design, vol. 86, no. 12, pp. 2865-2873, Dec. 2011, doi: 10.1016/j.fusengdes.2011.06.009.

[7] S. Carpentier-Chouchana et al., "Status of the ITER full-tungsten divertor shaping and heat load distribution analysis," Phys. Scr., vol. T159, p. 014002, Apr. 2014, doi: 10.1088/0031-8949/2014/T159/014002.

[8] Y. Corre et al., "Methodology for heat flux investigation on leading edges using infrared thermography," Nucl. Fusion, vol. 57, no. 1, p. 016009, Oct. 2016, doi: 10.1088/00295515/57/1/016009. 
[9] R. Dejarnac, J. P. Gunn, P. Vondracek, M. Komm, R. Panek, and R. A. Pitts, "Physics of toroidal gap heat loading on castellated plasma-facing components," Nuclear Materials and Energy, vol. 19, pp. 19-27, May 2019, doi: 10.1016/j.nme.2019.02.010.

[10] J. W. Coenen et al., "ELM-induced transient tungsten melting in the JET divertor," Nucl. Fusion, vol. 55, no. 2, p. 023010, Jan. 2015, doi: 10.1088/0029-5515/55/2/023010.

[11] J. W. Coenen et al., "ELM induced tungsten melting and its impact on tokamak operation," Journal of Nuclear Materials, vol. 463, pp. 78-84, Aug. 2015, doi: 10.1016/j.jnucmat.2014.08.062.

[12] Y. Corre et al., "Thermal analysis of protruding surfaces in the JET divertor," Nucl. Fusion, vol. 57, no. 6, p. 066009, Apr. 2017, doi: 10.1088/1741-4326/aa687e.

[13] J. Gaspar et al., "Heat flux analysis of Type-I ELM impact on a sloped, protruding surface in the JET bulk tungsten divertor," Nuclear Materials and Energy, vol. 17, pp. 182-187, Dec. 2018, doi: 10.1016/j.nme.2018.10.009.

[14] D. Iglesias et al., "An improved model for the accurate calculation of parallel heat fluxes at the JET bulk tungsten outer divertor," Nucl. Fusion, vol. 58, no. 10, p. 106034, Aug. 2018, doi: 10.1088/1741-4326/aad83e.

[15] K. Krieger et al., "Investigation of transient melting of tungsten by ELMs in ASDEX Upgrade," Phys. Scr., vol. T170, p. 014030, Oct. 2017, doi: 10.1088/1402-4896/aa8be8.

[16] J. W. Coenen et al., "Tungsten melt layer motion and splashing on castellated tungsten surfaces at the tokamak TEXTOR," Journal of Nuclear Materials, vol. 415, no. 1, Supplement, pp. S78-S82, Aug. 2011, doi: 10.1016/j.jnucmat.2010.09.046.

[17] R. E. Nygren et al., "Thermal management of tungsten leading edges in DIII-D," Fusion Engineering and Design, vol. 124, Apr. 2017, doi: 10.1016/j.fusengdes.2017.04.060.

[18] S. Hong et al., "Inter-ELM heat loads on tungsten leading edge in the KSTAR divertor," Nuclear Materials and Energy, vol. 12, pp. 1122-1129, Aug. 2017, doi: 10.1016/j.nme.2017.02.005.

[19] T. W. Morgan, M. A. van den Berg, G. D. Temmerman, S. Bardin, D. U. B. Aussems, and R. A. Pitts, "Power deposition on misaligned castellated tungsten blocks in the Magnum-PSI and Pilot-PSI linear devices," Nucl. Fusion, vol. 57, no. 12, p. 126025, Sep. 2017, doi: 10.1088/1741-4326/aa8109.

[20] T. W. Morgan et al., "A high-repetition rate edge localised mode replication system for the Magnum-PSI and Pilot-PSI linear devices," Plasma Physics and Controlled Fusion, vol. 56, no. 9, p. 095004, Sep. 2014, doi: 10.1088/0741-3335/56/9/095004.

[21] M. Missirlian et al., "The WEST project: Current status of the ITER-like tungsten divertor," Fusion Engineering and Design, vol. 89, no. 7, pp. 1048-1053, Oct. 2014, doi: 10.1016/j.fusengdes.2014.01.050.

[22] M. Houry et al., "The very high spatial resolution infrared thermography on ITER-like tungsten monoblocks in WEST Tokamak," Fusion Engineering and Design, vol. 146, pp. 1104-1107, Sep. 2019, doi: 10.1016/j.fusengdes.2019.02.017.

[23] Y. Corre et al., Integration of fiber Bragg grating temperature sensors in plasma facing components of the WEST tokamak, vol. 89. 2018.

[24] M. Firdaouss et al., "Operational limits on WEST inertial divertor sector during the early phase experiment," Physica Scripta, vol. T167, p. 014012, Feb. 2016, doi: 10.1088/00318949/2016/T167/014012.

[25] M. Diez et al., "First evidence of optical hot spots on ITER-like plasma facing units in the WEST tokamak," Nucl. Fusion, Feb. 2020, doi: 10.1088/1741-4326/ab7891. 
[26] J. Gaspar et al., "Emissivity measurement of tungsten plasma facing components of the WEST tokamak," Fusion Engineering and Design, vol. 149, p. 111328, Dec. 2019, doi: 10.1016/j.fusengdes.2019.111328.

[27] Th. Loewenhoff, J. Linke, G. Pintsuk, and C. Thomser, "Tungsten and CFC degradation under combined high cycle transient and steady state heat loads," Fusion Engineering and Design, vol. 87, no. 7, pp. 1201-1205, Aug. 2012, doi: 10.1016/j.fusengdes.2012.02.106.

[28] M. Firdaouss, T. Batal, J. Bucalossi, P. Languille, E. Nardon, and M. Richou, "Heat flux depositions on the WEST divertor and first wall components," Fusion Engineering and Design, vol. 98-99, pp. 1294-1298, Oct. 2015, doi: 10.1016/j.fusengdes.2014.12.024.

[29] T. Eich et al., "Empiricial scaling of inter-ELM power widths in ASDEX Upgrade and JET," Journal of Nuclear Materials, vol. 438, pp. S72-S77, Jul. 2013, doi: 10.1016/j.jnucmat.2013.01.011.

[30] J. Gaspar et al., "First heat flux estimation in the lower divertor of WEST with embedded thermal measurements," Fusion Engineering and Design, vol. 146, pp. 757-760, Sep. 2019, doi: 10.1016/j.fusengdes.2019.01.074.

[31] R. Dejarnac, M. Komm, J. P. Gunn, and Z. Pekarek, "Effect of misaligned edges and magnetic field orientation on plasma deposition into gaps during ELMs on ITER," Journal of Nuclear Materials, vol. 415, no. 1, Supplement, pp. S977-S980, Aug. 2011, doi: 10.1016/j.jnucmat.2010.09.042. 